\title{
SELEÇÃO DE CLONES DE COFFEA CANEPHORA PARA O PROCESSO DE COLHEITA MECANIZADA NO NORTE DO ESPÍRITO SANTO
}

\author{
SELECTION OF COFFEA CANEPHORA CLONES FOR THE MECHANIZED \\ HARVESTING PROCESS IN NORTHERN ESPÍRITO SANTO
}

${ }^{1}$ Joao Felipe de Brites Senra*.
${ }^{2}$ Gustavo Soares de Souza.
${ }^{3}$ César Abel Krohling.
${ }^{4}$ Matheus Wandermurem da Silva.
${ }^{5}$ Rodolfo Ferreira de Mendonça.
${ }^{6}$ Marcio Antônio Apostólico.

${ }^{1}$ Instituto Capixaba de Pesquisa, Assistência Técnica e Extensão Rural, Centro de Pesquisa, Desenvolvimento e Inovação Sul. E-mail: joao.senra@incaper.es.gov.br. ${ }^{2}$ Instituto Federal de Educação, Ciência e Tecnologia do Espírito Santo, Campus Itapina, E-mail: gustavo.souza@ifes.edu.br.

${ }^{3}$ Instituto Capixaba de Pesquisa, Assistência Técnica e Extensão Rural, Centro de Pesquisa, Desenvolvimento e Inovação Serrano, E-mail: cesar.kro@incaper.es.gov.br,

${ }^{4}$ Instituto Capixaba de Pesquisa, Assistência Técnica e Extensão Rural , Bolsista Consórcio Pesquisa Café. Email: matheus_wandermurem@hotmail.com.

${ }^{5}$ Prefeitura Municipal de Itapemirim, ES. Ex-bolsista Pos Doctor Junior CNPq e Consórcio Pesquisa Café no INCAPER. E-mail: rodolfofmendonca@gmail.com. ${ }^{6}$ Bolsista FAPES, Eng ${ }^{\circ}$ Agr $^{\circ}$, CCAE-UFES, Alegre/ES. E-mail: marcioapostolico84@yahoo.com.br. *Autor de correspondência

Artigo submetido em 13/08/2020, aceito em 09/11/2020 e publicado em 23/12/2020.

Resumo: Este trabalho objetiva selecionar clones de café conilon para o desenvolvimento de variedades adaptadas a colheita mecanizada. O estudo foi realizado em uma lavoura comercial no município de São Mateus. Os cafeeiros foram plantados em um espaçamento de 3,5 m entre linhas de cultivo e 0,5 m entre plantas. Foram avaliadas a produtividade em sacas de $60 \mathrm{~kg}$ beneficiadas por hectare (sc.ha-1), desfolha em kg de massa foliar desprendida das parcelas após a colheita $\left(\mathrm{kg} . \mathrm{ha}^{-1}\right)$ e porcentagem de plantas mortas por parcela (\%). A colheita mecanizada foi por meio de uma colhedora de café CaseIH modelo Coffee Express 200. Aplicou-se os modelos lineares mistos em blocos completos com 27 genótipos, duas repetições, duas colheitas e dois ambientes. Estimaram-se os componentes de variância, valores genéticos preditos e os intervalos de confiança. A diversidade genética dos clones foi analisada com base nos valores genéticos por meio da matriz de distâncias estatísticas de Mahalanobis seguido do agrupamento UPGMA e de Tocher Modificado. Não ocorreu interação dos genótipos com o ambiente. Os clones Tardio 9, Tardio 2, Intermediário 9, Precoce 6 e Tardio 3 apresentaram as maiores produtividades e baixa mortalidade de plantas e devem ser mantidos no programa de melhoramento do café conilon para colheita mecanizada. A maior distância estimada foi 37,56 entre os acessos Tardio 9 e Intermediário 7 e a menor foi 0,00 entre os acessos Tardio 1 e Precoce 6 . O agrupamento de Tocher formou sete grupos nos quais os clones Tardio 9, Tardio 6, Precoce 2 e Intermediário 9 ficaram isolados.

Palavras-chave: Melhoramento; interação genótipo x ambiente; análise multivariada; cafeicultura de conilon. 
Abstract: This work aims to select clones of conilon coffee for the development of varieties adapted to mechanized harvesting. The study was carried out in a commercial field in the municipality of São Mateus. The coffee trees were planted at a spacing of 3.5 between cultivation lines and 0.5 between plants. The following were evaluated: Productivity in $60 \mathrm{~kg}$ bags processed per hectare (sc.ha-1 ${ }^{-1}$; Defoliation in kg of leaf mass detached from the plots after harvest $\left(\mathrm{kg} \cdot \mathrm{ha} \mathrm{H}^{-1}\right)$; percentage of dead plants per plot (\%). Mechanized harvesting was done using a CaseIH coffee harvester model Coffee Express 200. Mixed linear models were applied in complete blocks with 27 genotypes, two replications, two harvests and two environments. The variance components, predicted genetic values and confidence intervals were estimated. The genetic diversity of the clones was analyzed based on the genetic values through the Mahalanobis statistical distance matrix followed by the UPGMA and Modified Tocher grouping. There was no interaction of genotypes with the environment. The clones Tardio 9, Tardio 2, Intermediário 9, Precoce 6 and Tardio 3 showed the highest productivity and low plant mortality and should be kept in the program of improvement of conilon coffee for mechanized harvest. The largest estimated distance was 37.56 between the Tardio 9 and Intermediário 7 accesses and the smallest was 0.00 between the Tardio 1 and Precoce 6 accessions. Tocher's cluster formed seven groups in which the Tardio 9, Tardio 6, Precoce clones 2 and Intermediate 9 were isolated.

Keywords: Breeding plants; genotype x environment interaction; multivariate analysis; conilon coffee.

\section{INTRODUÇÃO}

A cafeicultura está presente em mais de 80 países ocupando 11 milhões de hectares (DENOEUD et al., 2014) representando uma cadeia produtiva de bilhões de dólares (ICO, 2018). O comércio internacional de café concentra-se nas espécies Coffea arabica (café arábica), 60\% do mercado, e Coffea canephora (café conilon/robusta), 40\% do mercado (ICO, 2018). O Brasil é o maior produtor e exportador de café respondendo por 37\% da produção mundial (USDA, 2019) ocupando 2,13 milhões de hectares do território brasileiro (CONAB, 2019). A produção de cafés brasileiros foi de 49,97 milhões de sacas de $60 \mathrm{~kg}$ em 2019 e estima-se que atinja 59,58 milhões de sacas em 2020 sendo 16 milhões de conilon (CONAB, 2020). O estado do Espírito Santo destacase como o maior produtor de café conilon do país e o segundo maior produtor nacional de café (CONAB, 2019).

A cafeicultura capixaba encontra-se diante do desafio da escassez de mão de obra no campo e seu alto custo (SOUZA et al., 2020). A falta de mão de obra é atribuída à baixa disponibilidade de trabalhadores nas áreas rurais e salários mais baixos do que aqueles que eles podem receber nos centros urbanos (SILVA et al., 2013; SOUZA et al., 2017). Essa redução da disponibilidade de operários no campo eleva o preço da mão de obra, principalmente na ocasião da colheita, o que aumenta as estimativas dos preços da colheita dificultando gerenciamento agrícola e, consequentemente, torna o café capixaba menos competitivo no mercado nacional e internacional (LANNA; REIS, 2012; SOUZA et al., 2017). Uma alternativa para contornar a escassez de mão de obra é a adoção da mecanização agrícola na ocasião da colheita.

O uso da mecanização agrícola possibilitou o aumento da produção de diversas culturas no Brasil (FERREIRA JÚNIOR et al., 2016). A utilização de maquinário na agricultura multiplica o trabalho, reduz o tempo gasto com atividades manuais e aumenta a produtividade e o lucratividade dos agricultores (FERNANDES et al., 2013). No Brasil nas últimas décadas observou-se um avanço no uso de máquinas no cultivo de café arábica (CUNHA et al., 2016) e 
mais recentemente no café conilon (SOUZA et al., 2017). O estado do Espírito Santo apresenta 2,47 milhões de hectares com atividade agrícola e deste total, 29,6; 16,9 e $13,9 \%$ tem o potencial de mecanização extremamente alto, muito alto e alto, respectivamente, representando um total de 60,4\% da área com uso agrícola (SOUZA et al., 2019). O estado do Espírito Santo apresenta respectivamente $24,5 \%$ e 66,9 \% das lavouras de café arábica e conilon aptas a mecanização agrícola, o que reduz a dependência por mão de obra e diminui o custo de produção (SOUZA et al., 2019).

O principal método de colheita mecanizada na cafeicultura utiliza a vibração das hastes em máquinas de autopropulsão ou tração. Com a vibração as hastes promovem uma força de excitação nos frutos. Quando essa força é maior que a força de remoção entre o fruto e a planta, ocorre o desapego do fruto (CRISOSTO; NAGAO, 1991). Variações nos ajustes da colhedora de café alteram a eficiência do processo e são necessários para cada colheita (SILVA et al., 2013, 2015; SANTINATO et al., 2015). Os ajustes afetam diretamente no nível de danos e desfolhamento que as plantas sofrem ao passarem pelas vibrações das hastes da colhedora (OLIVEIRA et al., 2007; CASSIA et al., 2013). O processo de colheita mecânica pode ser entendido como um sistema de manejo para o qual os cafeeiros devem ser tolerantes pois o processo de desfolha pode ser desgastante para algumas plantas podendo levar até a falhas no estande de plantio devido a morte das mesmas provocando a perda de produtividade.

A colheita mecânica já é aplicada para o café arábica, mas os estudos para o conilon ainda são pioneiros e tentam elucidar o binômio regulagem do maquinário e escolha do material genético. Os cultivares desenvolvidos pelo programa de melhoramento genético do Instituto Capixaba de Pesquisa, Assistência Técnica e Extensão Rural (Incaper) são avaliados em condições de colheita manual e, portanto, não se sabe qual o comportamento destes em condições de colheita mecânica. Desta forma em virtude da necessidade de otimização da mão de obra na colheita e do potencial inexplorado à mecanização agrícola das lavouras capixabas o objetivo deste trabalho foi selecionar clones de café conilon para o processo de colheita mecânica, através do método de vibração das hastes, com maior produtividade, menor desfolha e porcentagem de plantas mortas.

\section{MATERIAIS E MÉTODOS}

O estudo foi realizado em uma lavoura comercial de café conilon no município de São Mateus, estado do Espírito Santo, Brasil (18\%43'34 "S, $40^{\circ} 00^{\prime} 28^{\prime \prime} \mathrm{W}$, a $72 \mathrm{~m}$ de altitude). O clima da região é do tipo Aw segundo a classificação de Köppen-Geiger (ALVARES et al., 2013), com uma precipitação média anual de $1.313 \mathrm{~mm}$, temperatura anual média de $24,1^{\circ} \mathrm{C}$ e topografia plana. $\mathrm{O}$ experimento foi instalado em outubro de 2012 com 27 clones separados em três grupos conforme seu padrão de amadurecimento: 9 clones de maturação precoce denominados de Precoce 1 a Precoce 9; 9 clones de maturação intermediária denominados Intermediário 1 a Intermediário 9; e 9 clones com maturação tardia denominados Tardio 1 a Tardio 9. Esses clones foram selecionados no banco ativo de germoplasma presente na Fazenda Experimental de Marilândia do Instituto 
Capixaba de Pesquisa, Assistência Técnica e Extensão Rural (Incaper). Os clones selecionados apresentavam baixo índice de tombamento, altura entre 1,8 a 2,8 m, vigor elevado, alta produtividade ( $>4.800$ kg.ha ${ }^{-1}$ de grãos beneficiados) e tamanho do grão acima da peneira 12 .

Os cafeeiros foram plantados em um espaçamento de 3,5 m entre linhas de cultivo e $0,5 \mathrm{~m}$ entre plantas (5714 plantas por hectare), conduzidos com dois ramos ortotrópicos por planta e 32 plantas por parcela. O solo da região é um argissolo amarelo distrófico (SANTOS et al., 2013). A adubação de plantio, condução e produção seguiu o manual de adubação e calagem para o estado do Espírito Santo (PREZOTTI et al., 2007). Os tratos culturais e fitossanitários foram realizados de acordo com a exigência da cultura, seguindo as recomendações atuais para o café conilon propostas por Ferrão et al., (2017).

A colheita mecânica foi por meio de uma colhedora de café da marca CaseIH modelo Coffee Express 200 (CaseIH Piracicaba-SP, Brasil). Esta máquina possui 55 hp, com rotação nominal do motor de 2.500 rpm. $\mathrm{min}^{-1}$, tração nas quatro rodas, pneus de alta flutuação 500/60-15.5, dois rolos agitadores verticais com hastes dispostas paralelamente ao tanque horizontal, a granel, lateral sistema de descarga e dimensões de 3,27 m de altura total e 3,50 m de largura operacional. A máquina se move sobre as plantas que estão em contato nas laterais com as hastes, que vibram e retiram o fruto através do impacto e da vibração transmitida à planta (SILVA et al., 2015; VILLIBOR et al., 2016). Dessa forma, os frutos descem nas placas sobrepostas que selam o fundo da colhedora. Os frutos escorregam nas placas sobrepostas e vão para os transportadores laterais em ambos os lados dos cafeeiros

Foram avaliadas três características neste estudo: Produtividade em sacas de $60 \mathrm{~kg}$ beneficiadas por hectare $\left(\mathrm{sc} \mathrm{ha}^{-1}\right)$; Desfolha em kg de massa foliar desprendida das parcelas após a colheita $\left(\mathrm{kg} \cdot \mathrm{ha}^{-1}\right)$; e porcentagem de plantas mortas por parcela (\%). As produtividades dos clones foram mensuradas em três plantas por parcela. A altura das hastes da colhedora foi ajustada para a região com frutos nas plantas. Foram utilizadas as velocidades de 0,6 e $0,8 \mathrm{~km} . \mathrm{h}^{-}$ ${ }^{1}$ e a frequência de vibração de $16,67 \mathrm{~Hz}$ (1.000 rpm). A desfolha foi medida após a determinação da produtividade dos clones em três plantas por parcela para colheita manual e em dez plantas por parcela para colheita mecânica, após a colheita do café utilizando uma balança digital portátil. A porcentagem de plantas mortas foi obtida pela contagem direta da mesma no estande.

Aplicou-se a metodologia dos modelos lineares mistos (REML/BLUP Máxima Verossimilhança Restrita e Melhor Predição Linear não Viciada) utilizando o delineamento experimental blocos completos com Estabilidade e Adaptabilidade pelo método MHPRVG (Média Harmônica da Performance Relativa dos Valores Genotípicos) com 27 genótipos, duas repetições, duas colheitas (safras 2018 e 2019 nos meses de maio a julho), e dois ambientes (ambiente 1 colheita mecânica; ambiente 2 clones colheita manual tradicional). O modelo estatístico é dado por:

$$
y=X_{m}+Z_{g}+T_{p}+W_{i}+e
$$

onde $y$ é o vetor de dados, $m$ é o vetor dos efeitos aleatórios das combinações medição-repetição-local (assumidos como 
fixos) somados a média geral, $g$ é o vetor dos efeitos genotípicos (assumidos como aleatórios), $p$ é o vetor dos efeitos de ambiente permanente (parcelas, assumidos como aleatórios), $i$ é o vetor da interação genótipos $\mathrm{x}$ locais (assumidos como aleatórios) e $e$ é o vetor de erros ou resíduo (assumidos como aleatórios). As letras maiúsculas representam as matrizes de incidência para os referidos efeitos.

Com base neste modelo foram estimados os valores genéticos dos clones pelo BLUP e os seguintes componentes de variância (REML individual): $\mathrm{V}_{\mathrm{g}}$ : variância

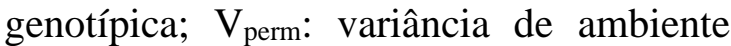
permante; $\quad V_{\text {int: }}$ variância da interação genótipos x locais; $\mathrm{V}_{\mathrm{e}}$ : variância residual; $\sigma_{\mathrm{e}}$ : desvio padrão residual; $\mathrm{V}_{\mathrm{f}}$ : variância fenotípica individual; $h^{2}$ : herdabilidade de parcelas individuais no sentido amplo; r: repetibilidade de parcelas individuais; c2perm: coeficiente de determinação dos efeitos de ambiente permanente; c2int: coeficiente de determinação dos efeitos da interação genótipos $\mathrm{x}$ locais; $\mathrm{h}^{2} \mathrm{mg}$ : herdabilidade média de genótipo considerando sobrevivência completa; $\mathrm{A}_{\text {cgen: }}$ Acurácia da seleção de genótipos, considerando sobrevivência completa; $\mathrm{CV}_{\text {gi\%: }}$ coeficiente de variação genotípica; $\mathrm{CV}_{\mathrm{e} \%}$ : coeficiente de variação residual; $\mathrm{CV}_{\mathrm{r} \% \text { : coeficiente de variação relativa; }}$ Média geral do experimento; valor $\mathrm{F}$ de Snedecor; o desvio padrão (SEP) e a variância do erro da predição (PEV); DMS: Diferença Mínima Significativa; LIIC: Limite Inferior do Intervalo de Confiança; LSIC: Limite Superior do Intervalo de Confiança.

Os valores do $\mathrm{CV}_{\mathrm{r} \%}, \mathrm{~F}$ e DMS foram estimados por:

$$
C V_{r \%}=\frac{C V_{g i \%}}{C V_{e \%}}
$$

$$
F=\frac{1}{\left(1-(\text { Acgen })^{2}\right)}
$$

$D M S$

$=1,4142 * t *\left(1-\frac{1}{F}\right)^{2}$

$* \frac{\sigma_{e}}{b^{\frac{1}{2}}}$, em que $b$ é o número de blocos

A diversidade genética dos clones foi analisada com base nos valores genéticos por meio da matriz de distâncias estatísticas de Mahalanobis (MAHALANOBIS, 1936) seguido do agrupamento hierárquico UPGMA e de otimização por Tocher Modificado (RAO, 1952; VASCONCELOS et al., 2007). Todas as análises estatísticas descritas foram realizadas pelo Sistema Estatístico de Seleção Genética computadorizada (Selegen) (RESENDE, 2016), o aplicativo computacional GENES (CRUZ, 2013; CRUZ, 2016) e programa $R$ (R CORE TEAM, 2019).

\section{RESULTADOS E DISCUSSÃO}

No processo de seleção genética é importante avaliar a qualidade do experimento para determinar a validade das inferências sobre os melhores genótipos. Um dos parâmetros mais importantes é a acurácia seletiva $\left(\mathrm{A}_{\text {cgen }}\right)$, que para fins de melhoramento genético deve ser superior a 0,7 e 0,9 para determinação dos valores de cultivo e uso de cultivares para lançamento (RESENDE, 2007).

De acordo com a Tabela 1 a característica produtividade apresenta uma boa acurácia demonstrando que nesta etapa do programa de melhoramento é possível diferir os clones com maior potencial produtivo. Para as demais características em avaliação faz-se necessário um maior número de colheitas. Outra informação importante é o coeficiente de variação 
relativo $\left(\mathrm{CV}_{\mathrm{r} \%}\right)$, que é uma razão entre coeficiente de variação genético e residual. Para atingir uma acurácia de 0,9 faz-se necessário, mantendo esse número de repetições, que o $\mathrm{CV}_{\mathrm{r}}$ seja igual 1,5 (RESENDE; DUARTE, 2007). Este valor indica que é necessário ampliar o número de colheitas para lançamento de cultivares, mas é um valor adequado para esta etapa inicial do programa de melhoramento.

Carias et al., (2016) avaliando a produtividade em oito famílias de meios irmãos na Fazenda Experimental de Marilândia (FEM), município de Marilândia, região Noroeste do estado do Espírito Santo, num experimento com três repetições e duas colheitas utilizando REML/BLUP, estimou valores de 0,6979, 0,5626 e 0,4870 para $A_{\text {cgen, }} C_{V_{r} \%}$ e herdabilidade média de genótipo $\left(\mathrm{h}^{2} \mathrm{mg}\right)$ respectivamente.

Esses valores são inferiores aos estimados neste trabalho (Tabela 1) demonstrando a qualidade do presente experimento. Carvalho et al. (2019) avaliando 20 progênies de irmãos completos em duas safras oriundas do cruzamento entre genótipos dos grupos botânicos conilon e robusta encontraram valores de 0,49, 0,15 e 0,45 para Acgen, herdabilidade de parcelas individuais no sentido amplo (h2) e h2mg respectivamente para a característica produtividade, herdabilidades próximas as estimadas nesta pesquisa. Esses valores de herdabilidade para produtividade foram próximos aos estimados na Costa do Marfim para Coffea canephora a partir dos cruzamentos entre grupos guineenses e congoleses (MONTAGNON et al., 2003).

A produtividade é uma característica fortemente influenciada pelo ambiente, a variabilidade genética dos materiais em avaliação e o número de colheitas em estudo. Os dados de produtividade avaliados ao longo de 14 anos revelaram maior herdabilidade em Camarões (CILAS et al., 2003). A literatura mostra que a produtividade é uma característica de baixa herdabilidade, sendo 0,0027 para o café arábica do Brasil (PETEK et al., 2008) e aproximadamente 0,26 para o café arábica de Camarões (CILAS et al., 1998).

Observa-se a inexistência da interação do genótipo com o ambiente, o que é verificado pelo valor nulo da variância da interação genótipos $\mathrm{x}$ locais ( $\left.\mathrm{V}_{\text {int }}\right)$ (Tabela 1) para as três características em estudo. Desta forma os valores genéticos preditos são válidos para ambos os ambientes e apresentados na Tabela 2. Os clones Tardio 9, Tardio 2, Intermediário 9, Precoce 6 e Tardio 3 apresentaram os maiores valores genéticos de produtividade. Os clones Tardio 9, Intermediário 9, Precoce 2, Intermediário 8 e Tardio 4 demonstraram os maiores níveis de desfolha. Os clones Intermediário 7, Precoce 4, Intermediário 3, Precoce 9 e Precoce 8 exibiram os maiores valores de Plantas Mortas.

Tabela 1: Componentes de variância estimados pelo método da máxima verossimilhança restrita dos 27 clones de Coffea canephora submetidos a colheita mecânica e colheita manual 
no município de São Mateus-ES, para as características Produtividade (Sc.ha ${ }^{-1}$ ), Desfolha $\left(K_{g} \cdot h^{-1}\right)$ e Plantas Mortas (\%).

\begin{tabular}{cccc}
\hline Componentes de & \multicolumn{3}{c}{ Características } \\
\cline { 2 - 4 } Variância & Produtividade & Desfolha & Plantas Mortas (\%) \\
\hline $\mathrm{V}_{\mathrm{g}}$ & 226.960 & 8525.491 & 6.770 \\
$\mathrm{~V}_{\text {perm }}$ & 257.137 & 54403.381 & 4.922 \\
$\mathrm{~V}_{\text {int }}$ & 0.000 & 0.000 & 0.000 \\
$\mathrm{~V}_{\mathrm{e}}$ & 748.220 & 283071.143 & 98.417 \\
$\sigma_{\mathrm{e}}$ & 27.353 & 532.044 & 9.920 \\
$\mathrm{~V}_{\mathrm{f}}$ & 1232.317 & 346000.016 & 110.109 \\
$\mathrm{~h}^{2}$ & 0.184 & 0.024 & 0.061 \\
$\mathrm{r}$ & 0.393 & 0.182 & 0.106 \\
$\mathrm{C}_{2 \mathrm{perm}}$ & 0.209 & 0.157 & 0.044 \\
$\mathrm{C}_{2 \text { int }}$ & 0.000 & 0.000 & 0.000 \\
$\mathrm{~h}^{2}{ }_{\mathrm{mg}}$ & 0.589 & 0.148 & 0.333 \\
$\mathrm{~A}_{\mathrm{cgen}}$ & 0.768 & 0.385 & 0.577 \\
$\mathrm{CV}_{\text {gi\% }}$ & 13.432 & 5.836 & 26.046 \\
$\mathrm{CV}_{\mathrm{e} \%}$ & 18.792 & 22.363 & 54.395 \\
$\mathrm{CV}_{\mathrm{r} \%}$ & 0.715 & 0.261 & 0.478 \\
Média Geral & 112.154 & 1582.024 & 9.989 \\
$\mathrm{~F}$ & 2.438 & 1.174 & 1.500 \\
$\mathrm{SEP}$ & 6.954 & 29.003 & 1.287 \\
$\mathrm{PEV}$ & 48.370 & 841.193 & 1.658
\end{tabular}

$\mathrm{V}_{\mathrm{g}}$ : variância genotípica; $\mathrm{V}_{\text {perm}}$ : variância de ambiente permante; $\mathrm{V}_{\text {int: }}$ variância da interação genótipos $\mathrm{x}$ locais; $\mathrm{V}_{\mathrm{e}}$ : variância residual; $\sigma_{\mathrm{e}}$ : desvio padrão residual; $\mathrm{V}_{\mathrm{f}}$ : variância fenotípica individual; $\mathrm{h}^{2}$ : herdabilidade de parcelas

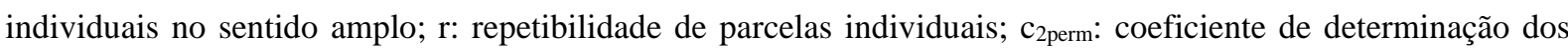
efeitos de ambiente permanente; $c_{2 \text { int: }}$ coeficiente de determinação dos efeitos da interação genótipos x locais; $\mathrm{h}^{2} \mathrm{mg}$ :

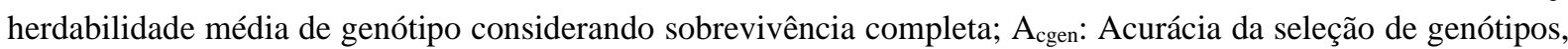
considerando sobrevivência completa; $\mathrm{CV}_{\text {gi\%: }}$ : coeficiente de variação genotípica; $\mathrm{CV}_{\mathrm{e} \%}$ : coeficiente de variação

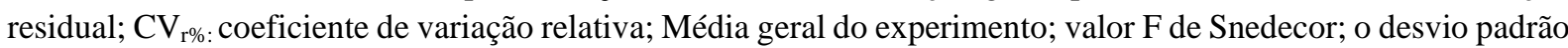
(SEP) e a variância do erro da predição (PEV).

Fonte: Elaborado pelos autores

Os clones mais produtivos possuem os maiores níveis de desfolha, pois, esta última é um desgaste inerente da colheita mais intensa. Apesar do alto nível de desfolha nos clones mais produtivos estes apresentaram os menores valores para a característica plantas mortas e, portanto, os níveis de desfolha não inviabilizam a seleção destes para composição de cultivares ou no programa de melhoramento. 
Tabela 2: Valores genéticos, média, variância e desvio padrão dos 27 clones de Coffea canephora submetidos a colheita mecânica e colheita manual no município de São Mateus-ES, para as características Produtividade (Sc.ha $\left.{ }^{-1}\right)$, Desfolha (Kg.ha ${ }^{-1}$ ) e Plantas Mortas (\%).

\begin{tabular}{cccc}
\hline Clones & \multicolumn{3}{c}{ Características } \\
\cline { 2 - 4 } & Produtividade & Desfolha & Plantas Mortas (\%) \\
\hline Precoce 1 & 119.973 & 1735.012 & 9.643 \\
Precoce 2 & 106.563 & 1965.965 & 11.691 \\
Precoce 3 & 109.180 & 1581.245 & 4.155 \\
Precoce 4 & 80.183 & 1294.786 & 25.000 \\
Precoce 5 & 95.436 & 1284.126 & 6.798 \\
Precoce 6 & 127.218 & 1674.377 & 3.646 \\
Precoce 7 & 110.404 & 1660.907 & 9.509 \\
Precoce 8 & 97.613 & 1379.829 & 13.245 \\
Precoce 9 & 98.159 & 1531.05 & 14.137 \\
Intermediário 1 & 96.311 & 1401.0635 & 10.2877 \\
Intermediário 2 & 115.225 & 1568.125 & 4.939 \\
Intermediário 3 & 88.280 & 1312.573 & 19.477 \\
Intermediário 4 & 108.316 & 1714.464 & 8.353 \\
Intermediário 5 & 111.289 & 1410.294 & 6.106 \\
Intermediário 6 & 103.143 & 1590.005 & 7.686 \\
Intermediário 7 & 58.056 & 740.326 & 27.92 \\
Intermediário 8 & 118.296 & 1841.009 & 8.005 \\
Intermediário 9 & 138.520 & 1978.157 & 4.602 \\
Tardio 1 & 110.799 & 1589.386 & 10.796 \\
Tardio 2 & 139.444 & 1496.846 & 6.720 \\
Tardio 3 & 126.614 & 1417.58 & 7.582 \\
Tardio 4 & 122.807 & 1794.584 & 8.275 \\
Tardio 5 & 115.145 & 1505.068 & 10.276 \\
Tardio 6 & 119.716 & 1467.861 & 13.008 \\
Tardio 7 & 124.308 & 1714.303 & 6.915 \\
Tardio 8 & 116.197 & 1553.821 & 5.581 \\
Tardio 9 & 170.956 & 2511.88 & \\
Média & 1582.024 & 9.989 \\
Variância & 94876.922 & \\
Desvio Padrão & 20.924 & 308.02 & \\
\hline
\end{tabular}

Fonte: Elaborado pelos autores

Uma melhor distinção entre os clones é possível contrastando seus valores genéticos preditos com os seus limites de confiança inferior e superior, apresentados na Tabela 3. Observa-se que os clones Tardio 9, Tardio 2, Intermediário 9, Precoce
6 e Tardio 3 devem ser mantidos no programa de melhoramento genético para colheita mecanizada devido à alta produtividade e baixa mortalidade de plantas. Os clones Intermediário 7, Precoce 4, Intermediário 3, Precoce 9 e Precoce 8 
devem ser descartados das próximas etapas do programa.

Tabela 3: Valores Genéticos (V.G.), Limite Inferior e Superior do Intervalo de Confiança (LIIC e LSIC) dos 27 clones de Coffea canephora submetidos a colheita mecânica e colheita manual no município de São Mateus-ES, para as características Produtividade (Sc.ha-1), Desfolha $\left(\mathrm{Kg} \mathrm{ha}^{-1}\right)$ e Plantas Mortas (\%).

\begin{tabular}{|c|c|c|c|c|c|c|c|c|c|c|c|}
\hline & \multicolumn{3}{|c|}{$\begin{array}{l}\text { Produtividade } \\
\end{array}$} & \multicolumn{4}{|c|}{ Desfolha } & \multicolumn{4}{|c|}{$\begin{array}{l}\text { Plantas Mortas (\%) } \\
\end{array}$} \\
\hline Clone* & V.G. & LIIC & LSIC & Clone $^{*}$ & V.G. & LIIC & LSIC & Clone* & V.G. & LIIC & LSIC \\
\hline T.9 & 170.96 & 151.68 & 190.23 & T. 9 & 2511.88 & 2431.49 & 2592.27 & I. 7 & 27.93 & 24.36 & 31.50 \\
\hline T.2 & 139.44 & 120.17 & 158.72 & I. 9 & 1978.16 & 1897.77 & 2058.55 & P. 4 & 25.00 & 21.43 & 28.57 \\
\hline I.9 & 138.52 & 119.24 & 157.80 & P. 2 & 1965.97 & 1885.57 & 2046.36 & I. 3 & 19.48 & 15.91 & 23.05 \\
\hline P.6 & 127.22 & 107.94 & 146.50 & I. 8 & 1841.01 & 1760.62 & 1921.40 & P. 9 & 14.14 & 10.57 & 17.71 \\
\hline T.3 & 126.61 & 107.34 & 145.89 & T. 4 & 1794.58 & 1714.19 & 1874.98 & P. 8 & 13.25 & 9.68 & 16.82 \\
\hline T.7 & 124.31 & 105.03 & 143.59 & P. 1 & 1735.01 & 1654.62 & 1815.40 & T. 6 & 13.01 & 9.44 & 16.58 \\
\hline T.4 & 122.81 & 103.53 & 142.09 & I. 4 & 1714.46 & 1634.07 & 1794.86 & P. 2 & 11.69 & 8.12 & 15.26 \\
\hline P. 1 & 119.97 & 100.70 & 139.25 & Т. 7 & 1714.30 & 1633.91 & 1794.70 & T. 1 & 10.80 & 7.23 & 14.37 \\
\hline T.6 & 119.72 & 100.44 & 138.99 & P. 6 & 1674.38 & 1593.99 & 1754.77 & I. 1 & 10.29 & 6.72 & 13.86 \\
\hline I.8 & 118.30 & 99.02 & 137.57 & P. 7 & 1660.91 & 1580.52 & 1741.30 & T. 5 & 10.28 & 6.71 & 13.85 \\
\hline Т.8 & 116.20 & 96.92 & 135.48 & I. 6 & 1590.01 & 1509.61 & 1670.40 & P. 1 & 9.64 & 6.07 & 13.21 \\
\hline I. 2 & 115.23 & 95.95 & 134.50 & T. 1 & 1589.39 & 1508.99 & 1669.78 & P. 7 & 9.51 & 5.94 & 13.08 \\
\hline T.5 & 115.15 & 95.87 & 134.42 & P. 3 & 1581.25 & 1500.85 & 1661.64 & I. 4 & 8.35 & 4.78 & 11.92 \\
\hline I.5 & 111.29 & 92.01 & 130.57 & I. 2 & 1568.13 & 1487.73 & 1648.52 & T. 4 & 8.28 & 4.71 & 11.84 \\
\hline T.1 & 110.80 & 91.52 & 130.08 & T. 8 & 1553.82 & 1473.43 & 1634.21 & I. 8 & 8.01 & 4.44 & 11.58 \\
\hline P.7 & 110.40 & 91.13 & 129.68 & P. 9 & 1531.05 & 1450.66 & 1611.45 & I. 6 & 7.69 & 4.12 & 11.26 \\
\hline P.3 & 109.18 & 89.90 & 128.46 & T. 5 & 1505.07 & 1424.68 & 1585.46 & T. 3 & 7.58 & 4.01 & 11.15 \\
\hline I. 4 & 108.32 & 89.04 & 127.59 & T. 2 & 1496.85 & 1416.45 & 1577.24 & P. 5 & 6.80 & 3.23 & 10.37 \\
\hline P. 2 & 106.56 & 87.29 & 125.84 & T. 6 & 1467.86 & 1387.47 & 1548.25 & T. 2 & 6.72 & 3.15 & 10.29 \\
\hline I.6 & 103.14 & 83.87 & 122.42 & T. 3 & 1417.59 & 1337.20 & 1497.98 & T. 8 & 6.44 & 2.87 & 10.01 \\
\hline P.9 & 98.16 & 78.88 & 117.44 & I. 5 & 1410.29 & 1329.90 & 1490.69 & I. 5 & 6.11 & 2.54 & 9.68 \\
\hline P.8 & 97.61 & 78.34 & 116.89 & I. 1 & 1401.06 & 1320.67 & 1481.46 & T. 7 & 5.82 & 2.25 & 9.38 \\
\hline I.1 & 96.31 & 77.03 & 115.59 & P. 8 & 1379.83 & 1299.44 & 1460.22 & T. 9 & 5.58 & 2.01 & 9.15 \\
\hline P.5 & 95.44 & 76.16 & 114.71 & I. 3 & 1312.57 & 1232.18 & 1392.97 & I. 2 & 4.94 & 1.37 & 8.51 \\
\hline I.3 & 88.28 & 69.00 & 107.56 & P. 4 & 1294.79 & 1214.39 & 1375.18 & I. 9 & 4.60 & 1.03 & 8.17 \\
\hline P. 4 & 80.18 & 60.91 & 99.46 & P. 5 & 1284.13 & 1203.73 & 1364.52 & P. 3 & 4.16 & 0.59 & 7.73 \\
\hline I.7 & 58.06 & 38.78 & 77.33 & I. 7 & 740.33 & 659.93 & 820.72 & P. 6 & 3.65 & 0.08 & 7.22 \\
\hline
\end{tabular}

* P. - Precoce; I. - Intermediário; T. - Tardio.

Fonte: Elaborado pelos autores 
Paralelo aos valores genéticos preditos o conhecimento da variabilidade genética dos materiais em avaliação é importante para definição dos clones selecionados para composição de variedades ou a próxima etapa do programa de melhoramento, no qual, os clones testar-se-ão em um maior número de repetições e locais. A Figura 1 representa o agrupamento UPGMA dos clones em avaliação com base na matriz de distância de Mahalanobis (matriz de distâncias estatísticas não apresentadas) estimada considerando os valores genéticos da produtividade, desfolha e porcentagem

de plantas mortas. Os clones com a mesma cor foram agrupados no mesmo grupo segundo o método de agrupamento de Tocher Modificado. Verifica-se a formação de sete grupos, nos quais os clones Tardio 9, Tardio 6, Precoce 2 e Intermediário 9 estão isolados, o que demonstra que além da superioridade agronômica possuem valor para manutenção da diversidade genética. A maior distância estimada foi 37,56 entre os acessos Tardio 9 e Intermediário 7 e a menor foi 0,00 entre os acessos Tardio 1 e Precoce 6.

Figura 1: Distância de Mahalanobis com base nos valores genéticos Produtividade (Sc.ha ${ }^{1}$ ), Desfolha (Kg.ha ${ }^{-1}$ ) e Plantas Mortas (\%) dos clones de C. canephora submetidos a colheita mecânica e colheita manual no município de São Mateus-ES. Os clones marcados com as mesmas cores pertencem aos mesmos grupos segundo o método de agrupamento de Tocher modificado.

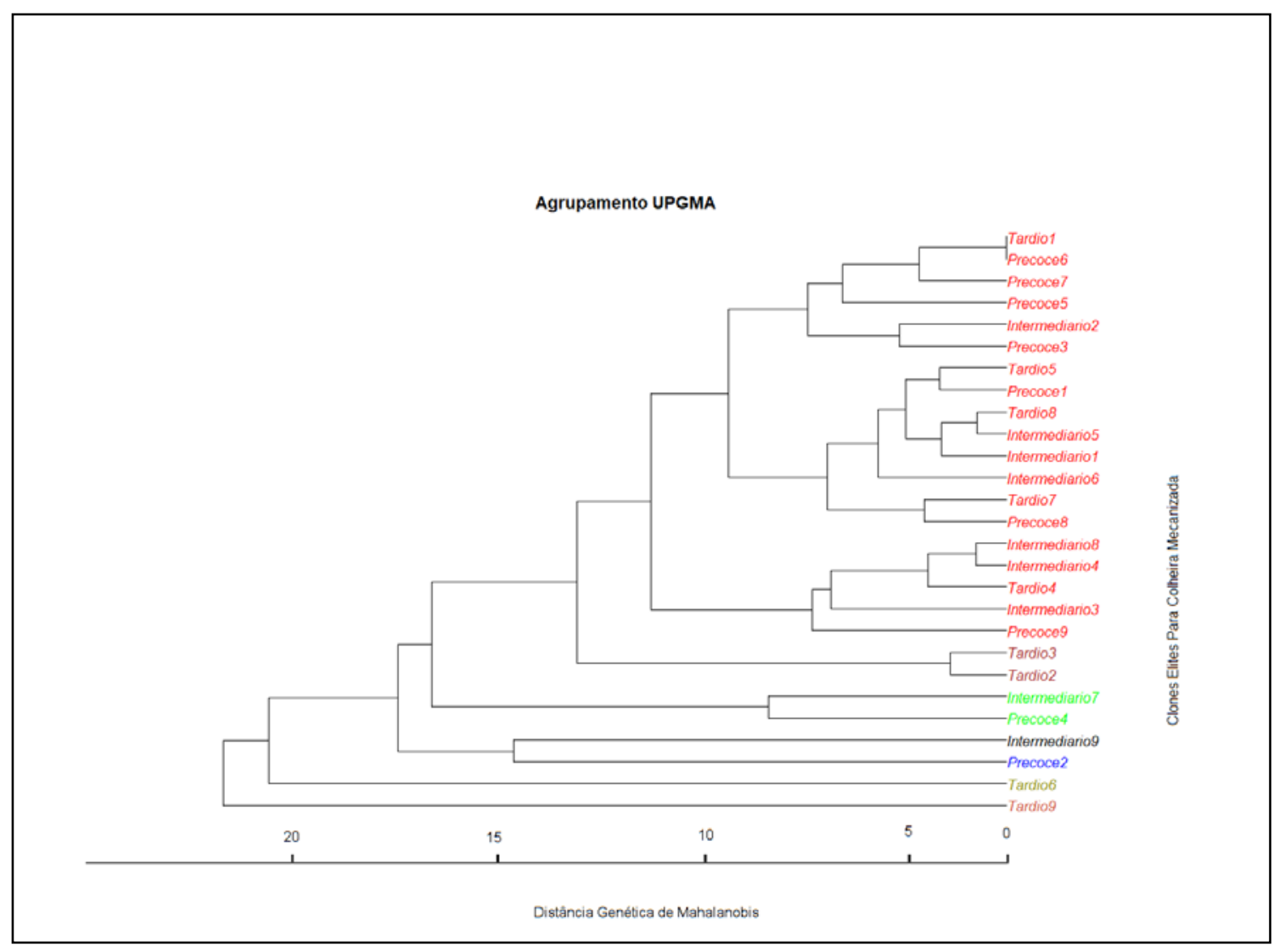

Fonte: Elaborado pelos autores 


\section{CONCLUSÕES}

Existe um expressivo controle da qualidade das estimativas dos valores genéticos de produtividade, possibilitando a diferenciação dos clones mais produtivos. Os valores de herdabilidade de parcelas individuais no sentido amplo e herdabilidade média de genótipo estão dentro dos valores estimados na literatura para a produtividade corroborando com a seleção de clones com maior potencial de produção.

Não ocorreu interação genótipo x ambiente e desta forma os valores genéticos preditos são válidos para sistemas com e sem colheita mecanizada. Os clones Tardio 9, Tardio 2, Intermediário 9, Precoce 6 e Tardio 3 apresentaram os maiores valores genéticos de produtividade. Os clones Tardio 9, Intermediário 9, Precoce 2, Intermediário 8 e Tardio 4 demonstraram os maiores níveis de desfolha. Os clones Intermediário 7, Precoce 4, Intermediário 3, Precoce 9 e Precoce 8 exibiram os maiores valores de Plantas Mortas. Os clones Tardio 9, Tardio 2, Intermediário 9, Precoce 6 e Tardio 3 devem ser mantidos no programa de melhoramento genético para colheita mecanizada devido à alta produtividade e baixa mortalidade de plantas. A maior distância estimada foi 37,56 entre os acessos Tardio 9 e Intermediário 7 e a menor foi 0,00 entre os acessos Tardio 1 e Precoce 6. O agrupamento de Tocher formou sete grupos nos quais os clones Tardio 9, Tardio 6, Precoce 2 e Intermediário 9 ficaram isolados.

\section{AGRADECIMENTOS}

Os autores gostariam de agradecer a Fundação de Amparo à Pesquisa e Inovação do Espírito Santo (FAPES) e ao Consórcio de Pesquisas Cafeeiras (Concafé) pelo suporte financeiro.

\section{REFERÊNCIAS}

ALVARES, C. A.; STAPE, J. L.; SENTELHAS, P. C.; GONÇALVES, J. L. de M.; SPAROVEK, G. Köppen's climate classification map for Brazil. Meteorologische Zeitschrift, Berlin, v. 22, n. 6, p. 711-728, 2013. DOI: https://doi.org/10.1127/09412948/2013/0507.

CARIAS, C. M. O. M.; GAVINA, G. A.; FERRÃO, M. A. G.; FONSECA, A. F. A.; FERRÃO, R. G.; VIVAS, M.; VIANA, A. P. Predição de ganhos genéticos via modelos mistos em progênies de café Conilon. Coffee Science, Lavras, v. 11, n. 1, p. 39 - 45, 2016.

CARVALHO, H. F.; SILVA, F. L.; RESENDE, M. D. V.; BHERING, L. Selection and genetic parameters for interpopulation hybrids between kouilou and robusta coffee. Bragantia, Campinas, v. 78, n. 1, p. 52 - 59, 2019. DOI:10.1590/1678-4499.2018124.

CASSIA, M. T.; SILVA, R. P.; CHIODEROLLI, C. A.; NORONHA, R. H. F.; SANTOS, E. P. Quality of mechanized coffee harvesting in circular planting system. Ciência Rural, Santa Maria, v. 43, n. 1, p. 2834, 2013. DOI:

https://doi.org/10.1590/S010384782012005000148.

CILAS, C.; BOUHARMONT, P.; BARHEN, A. Yield stability in Coffea canephora from diallel mating designs 
monitored for 14 years. Heredity, Oxford v. 91, p. 528-532, 2003. DOI: https://doi.org/10.1038/sj.hdy.6800351.

CILAS, C.; BOUHARMONT, P.; BOCCARA, M.; ESKES, A. B.; BARADAT, P. Prediction of genetic value for coffee production in Coffea arabica from a half-diallel with lines and hybrids. Euphytica, Wageningen, v. 104, p. 49-59, 1998.

\section{COMPANHIA NACIONAL DE} ABASTECIMENTO.

Acompanhamento da safra brasileira de café: Quarto levantamento, safra 2019. Brasília: Companhia Nacional de Abastecimento, v.5, n.4, 2019.

COMPANHIA NACIONAL DE ABASTECIMENTO. Acampamento da safra brasileira: café. Brasília: Companhia Nacional de Abastecimento, v. 6, n. 1, p. 1-62, 2020.

CRISOSTO, C. H.; NAGAO, M. A. Evaluation of fruit removal force of coffee cultivars. HortiScience, California, v. 26, n. 2, p. 210-230, 1991.

CRUZ C. D. GENES - a software package for analysis in experimental statistics and quantitative genetics. Acta Scientiarum Agronomy, Maringá, v. 35, n. 3, p. 271-276, 2013.

CRUZ C. D. Genes Software extended and integrated with the R, Matlab and Selegen. Acta Scientiarum Agronomy, Maringá, v. 38, n. 4, p. 547-552, 2016.

DOI:10.4025/actasciagron.v38i4.32629.

CUNHA, J. P. B.; SILVA, F. M.; ANDRADE, E. T.; CARVALHO, L. C. C. Modeling of operational performance parameters applied in mechanized harvest of coffee. Revista Brasileira de Engenharia Agrícola e Ambiental,
Campina Grande, v. 20, n.10, p. 946-952, 2016.

DENOEUD, F.; CARRETERO-

PAULET, L.; DEREEPER, A.; DROC, G.; GUYOT, R.; PIETRELLA, M.; ZHENG, C.; ALBERTI, A.;

ANTHONY, F.; APREA, G. 2014. The coffee genome provides insight into the convergent evolution of caffeine biosynthesis. Science, v. 345, p. 11811184, 2014.

FERNANDES, H. C.; BURLA, E. R.; LEITE, E. S.; MINETTE, L. J.

Avaliação técnica e econômica de um "Harvester" em diferentes condições de terreno e produtividade da Floresta.

Scientia Forestalis, Piracicaba, v. 41, n. 97, p. 145-151, 2013.

FERRÃO, R G.; FONSECA, A. F. A.; FERRÃO, M. A. G.; MUNER, L.H. 2017. Café Conilon. Vitória: DCM/Incaper, 784 p., 2017.

FERREIRA JUNIOR, L. G.; SILVA, F. M.; FERREIRA, D. D.; SALES, R. S. Recomendação para colheita mecânica do café baseado no comportamento de vibração das hastes derriçadoras.

Ciência Rural, Santa Maria, v. 46, n. 2, p. 273-278, 2016.

INTERNATIONAL COFFEE ORGANIZATION (ICO). 2018. Trade Statistics. Disponível em:

$<$ www.ico.org/ trade_statistics.asp $>$.

LANNA, G. B. M.; REIS, R. P. Influência da mecanização da colheita na viabilidade econômico-financeira da cafeicultura no sul de Minas Gerais. Coffee Science, Lavras, v. 7, n. 2, p. 110-121, 2012.

MAHALANOBIS, P. C. On the generalized distance in statistics. Proceedings of the National Institute 
of Sciences of India, New Delhi, v.2, p. 49-55, 1936.

MONTAGNON, C.; LEROY, T.; CILAS, C.; CHARRIER, A. Heritability of Coffea canephora yield estimated from several mating designs.

Euphytica, Wageningen, v. 133, p. 209-218, 2003. DOI: https://doi.org/10.1023/A:10255438056 52.

OLIVEIRA, E.; SILVA, F. M.; SOUZA, Z. M.; FIGUEIREDO, C. A. P. Influência da colheita mecanizada na produção cafeeira. Ciência Rural, Santa Maria, v. 37, p. 1466-1470, 2007.

PETEK, M. R.; SERA, T.; FONSECA, I. D. B. (2008). Predição de valores genéticos aditivos na seleção visando obter cultivares de café mais resistentes à ferrugem. Bragantia, Campinas, v . 67, 133-140, 2008.

PREZOTTI, L. C.; GOMES, J. A.; DADALTO, G. G.; OLIVEIRA, J. A. Manual de recomendação de calagem e adubação para o estado do Espírito Santo - $5^{\mathrm{a}}$ aproximação. Vitória, ES: SEEA/INCAPER/CEDAGRO, 305p., 2007.

R CORE TEAM (2019). R: A language and environment for statistical computing. R Foundation for Statistical Computing, Vienna, Austria. URL https://www.R-project.org/.

RAO, R. C. Advanced statistical methods in biometric research. New York: J. Wiley, 330 p., 1952.

RESENDE, M. D. V.; DUARTE, J. B. Precisão e controle de qualidade em experimentos de avaliação de cultivares. Pesquisa Agropecuária Tropical, Goiânia, v. 37, n. 3, p. 182-194, 2007.
Resende, M. D. V.

Matemática e estatística na análise de experimentos e no melhoramento genético. Colombo - PR. p. 362, 2007.

RESENDE, M. D. V. Software SelegenREML/BLUP: a useful tool for breeding. Crop Breeding and Applied Biotechnology, Viçosa, v. 16, p. 330339, 2016.

SANTINATO, F.; SILVA, C. D.; SILVA, R. P.; RUAS, R. A. A.; FERNANDES, A. L. T.; SANTINATO, R. Colheita mecanizada do café em lavouras de primeira safra. Revista Brasileira de Engenharia Agrícola e Ambiental, Campina Grande, v. 19, p. 1215-1219, 2015. DOI: https://doi.org/10.1590/18071929/agriambi.v19n12p1215-1219.

SANTOS, H. G.; JACOMINE, P. K. T.; ANJOS, L. H. C.; OLIVEIRA, V. A.; LUMBRERAS, J. F.; COELHO, M. R.; ALMEIDA, J. A.; CUNHA, T. J. F.; OLIVEIRA, J. B. de. Sistema brasileiro de classificação de solos. 3.ed. Brasília, 353p., 2013.

SILVA, F. C.; SILVA, F. M.; ALVES, M. C.; FERRAZ, G. A. S.; SALES, R. $S$. Efficiency of coffee mechanical and selective harvesting in different vibration during harvest time. Coffee Science, Lavras, v. 10, p. 56-64, 2015.

SILVA, F. C.; SILVA, F. M.; SILVA, A. C.; BARROS, M. M.; PALMA, M. A. Z. Desempenho operacional da colheita mecanizada e seletiva do café em função da força de desprendimento dos frutos. Coffee Science, Lavras, v. 8, p. 53-60, 2013.

SOUZA, G. S.; LANI, J. A.; INFANTINI, M. B.; KROHLING, C. A.; SENRA, J. F. B. Mechanized harvesting of 'Conilon' coffee clones. 
Pesquisa Agropecuária Brasileira, Brasília, v. 55, e01240, 2020.

SOUZA, G. S.; LANI, J. A.;

INFANTINI, M. B.; SILVA, F. M.;

ALVES, E. A.; BUENO, R. L. Colheita mecanizada do café conilon. In:

FERRÃO, R.G; FONSECA, A.F.A.; FERRÃO, M.A.G.; DE MUNER, L.H. Café conilon. 2ed. Vitória, p. 509-530, 2017.

SOUZA, G. S.; TAQUES, R. C.; SENRA, J. F. B.; LANI, J. A. Potencial de mecanização das lavouras cafeeiras no estado do espírito santo. Em: Silva, C.A.P.; Nicoli, C.F. et al. (Org.). 29

Semana agronômica do CCAE-UFES. Centro de Ciências Agrárias e Engenharias UFES, p. 55-67, 2019.
USDA. United states II: department of agriculture. Production, Supply and Distribuition. 2019.

Disponível em: $<$ https://apps.fas.usda. gov/psdonline/app/index.html\#/app/dow nloads>.

VASCONCELOS, E. S.; CRUZ, C.D.; BHERING, L.L.; RESENDE JÚNIOR, M.F.R. Método Alternativo para Análise de Agrupamento. Pesquisa Agropecuária Brasileira, Brasília, v. 42, n. 10, p. 1421-1428, 2007.

VILLIBOR, G. P.; SANTOS, F. L.; QUEIROZ, D. M.; KHOURY JUNIOR, J. K.; PINTO, F. A. C. Determination of modal properties of the coffee fruitstem system using high speed digital video and digital image processing.

Acta Scientiarum Technology,

Maringá, v.38, p.41-48, 2016. 